www.nature.com/ejhg

\title{
Mapping of a new autosomal recessive nonsyndromic hearing loss locus (DFNB32) to chromosome 1p13.3-22.1
}

\author{
Saber Masmoudi ${ }^{1}$, Abdelaziz Tlili ${ }^{1}$, Marja Majava ${ }^{2}$, Abdel Monem Ghorbel ${ }^{3}$, \\ Sébastien Chardenoux ${ }^{4}$, Arnaud Lemainque ${ }^{5}$, Zeineb Ben Zina ${ }^{6}$, Jihene Moala ${ }^{3}$, \\ Minna Männikkö ${ }^{2}$, Dominique Weil ${ }^{4}$, Mark Lathrop ${ }^{5}$, Leena Ala-Kokko ${ }^{2,7}$, \\ Mohamed Drira ${ }^{3}$, Christine Petit $^{4}$ and Hammadi Ayadi*,1
}

${ }^{1}$ Laboratoire de Génétique Moléculaire Humaine, Faculté de Médecine Sfax, Tunisie; ${ }^{2}$ Collagen Research Unit, Biocenter and Department of Medical Biochemistry and Molecular Biology, University of Oulu, Oulu, Finland; ${ }^{3}$ Service d'O.R.L., C.H.U. H. Bourguiba Sfax, Tunisie; ${ }^{4}$ Unité de Génétique des Déficits Sensoriels, Institut Pasteur Paris, France; ${ }^{5}$ Centre National de Génotypage, Evry, France; ${ }^{6}$ Service d'Ophtalmologie, C.H.U. H. Bourguiba, 3018, Sfax, Tunisie; ${ }^{7}$ Center for Gene Therapy and Department of Medicine, Tulane University Health Sciences Center, New Orleans, Louisiana, LA, USA

Approximately $\mathbf{8 0} \%$ of the hereditary hearing loss is nonsyndromic. Isolated deafness is the most genetically heterogeneous trait. We have ascertained 10 individuals from a large consanguineous Tunisian family with congenital profound autosomal recessive deafness. All affected individuals are otherwise healthy. Genotype analysis excluded linkage to known recessive deafness loci in this family. Following a genome wide screening, a linkage was detected only with locus D1S206 on chromosome 1, thereby defining a novel deafness locus, DFNB32. In order to confirm linkage and for fine mapping the genetic interval, 12 individuals belonging to this family were added and 19 microsatellite markers were tested. A maximum two-point lodscore of 4.96 was obtained at a new polymorphic marker D1S21401. Haplotype analysis defined a $16 \mathrm{Mb}$ critical region between D1S2868 and afmb014zb9. The interval of DFNB32 locus overlap with DFNA37 locus and the Marshall and Stickler syndromes locus. The entire coding region of $C O L 11 A 1$, responsible of the later syndromes, was screened and no mutation was observed. Towards the identification of the DFNB32 gene, a search on the Human Cochlear cDNA Library and EST Database was done. The genes corresponding to the ESTs found in the DFNB32 interval are being screened for deafness-causing mutations.

European Journal of Human Genetics (2002) 11, 185 -188. doi:10.1038/sj.ejhg.5200934

Keywords: Nonsyndromic hearing impairment; gene localisation; DFNB32; mutation analysis; COL11A1

\section{Introduction}

Hearing impairment is the most frequently inherited human sensory defect. Approximately one in 1000 children

\footnotetext{
*Correspondence: Hammadi Ayadi, Laboratoire de Génétique Moléculaire Humaine, Faculté de Médecine, 3018 Sfax, Tunisie. Tel: 21674241888 (350); Fax: 21674246946 ;

E-mail: hammadi.ayadi@fmsf.rnu.tn

Received 10 July 2002; revised 12 November 2002; accepted 14 November 2002
}

is affected with prelingual deafness and at least $50 \%$ of these cases are hereditary. ${ }^{1,2}$ In $80 \%$ of these cases, the hearing impairment is described as nonsyndromic, because it is not associated with other disorders. ${ }^{3}$ Isolated deafness forms transmitted in the recessive mode are the most frequent $(85 \%)$ and the most severe. ${ }^{1}$ Thirty-one different DFNB loci have been mapped and 13 of the corresponding genes have been identified (http://www.uia.ac.be/dnalab/ $\mathrm{hhh} /$ ). We have investigated a large consanguineous Tuni- 
sian family segregating an autosomal recessive nonsyndromic hearing loss and mapped the gene responsible for this defect to chromosome 1p13.3-22.1.

\section{Materials and methods}

\section{Subjects}

We analysed a large consanguineous Tunisian family in which nonsyndromic hearing impairment is transmitted as an autosomal recessive trait (Figure 1). Individuals were evaluated for hearing loss by clinical examination and audiological tests including pure tone audiometry and evoked response audiometry. Air-conduction pure-tone average (ACPTA) thresholds in the conversational frequencies $(0.5,1$ and $2 \mathrm{kHz})$ were calculated for each ear, and were used to define the severity of the hearing loss according to the better hearing ear: mild $(25 \mathrm{~dB} \leqslant \mathrm{ACPTA} \leqslant 39 \mathrm{~dB})$, moderate $(40 \mathrm{~dB} \leqslant \mathrm{ACPTA} \leqslant 69 \mathrm{~dB})$, severe $(70 \mathrm{~dB} \leqslant \mathrm{ACP}$ $\mathrm{TA} \leqslant 89 \mathrm{~dB}$ ) and profound (ACPTA $\geqslant 90 \mathrm{~dB}$ ). All affected individuals are otherwise healthy. Syndromic forms of hearing loss had been excluded. Appropriate informed consent was obtained from all subjects.

\section{Genotyping and linkage analysis}

Genomic DNA was extracted using a standard phenolchloroform technique from $10 \mathrm{ml}$ blood samples. The genome-wide screening was performed using 400 microsatellite markers at intervals of $10 \mathrm{~cm}$ (ABI PRISM 1 Linkage Mapping Set 2, Applied Biosystems). Multiplex PCR were performed with four markers. PCR products were analysed following electrophoresis on a $6 \%$ polyacrylamide gel. In order to confirm linkage and for fine mapping the genetic interval, 19 additional polymorphic microsatellite markers were typed, comprising 18 published (http://cedar. genetics.soton.ac.uk/pub/chrom1/map.html) and one new marker (D1S21401), which was determined by searching for possible (CA) repeats in the sequence data of BAC clones between markers D1S1166 and afmb014zb9. The PCR primers for the new marker were D1S21401F (AGAATTTGGAGGTTTTTGGG)/ D1S21401R (TTGCATCCAGGACTTTTGTT). PCR products were analysed on $6 \%$ denaturing polyacrylamide gels, transferred onto $\mathrm{N}^{+}$-Hybond membrane (Amersham) and hybridized with a polyAC probe labelled with $\alpha^{32} \mathrm{P}$ dCTP.

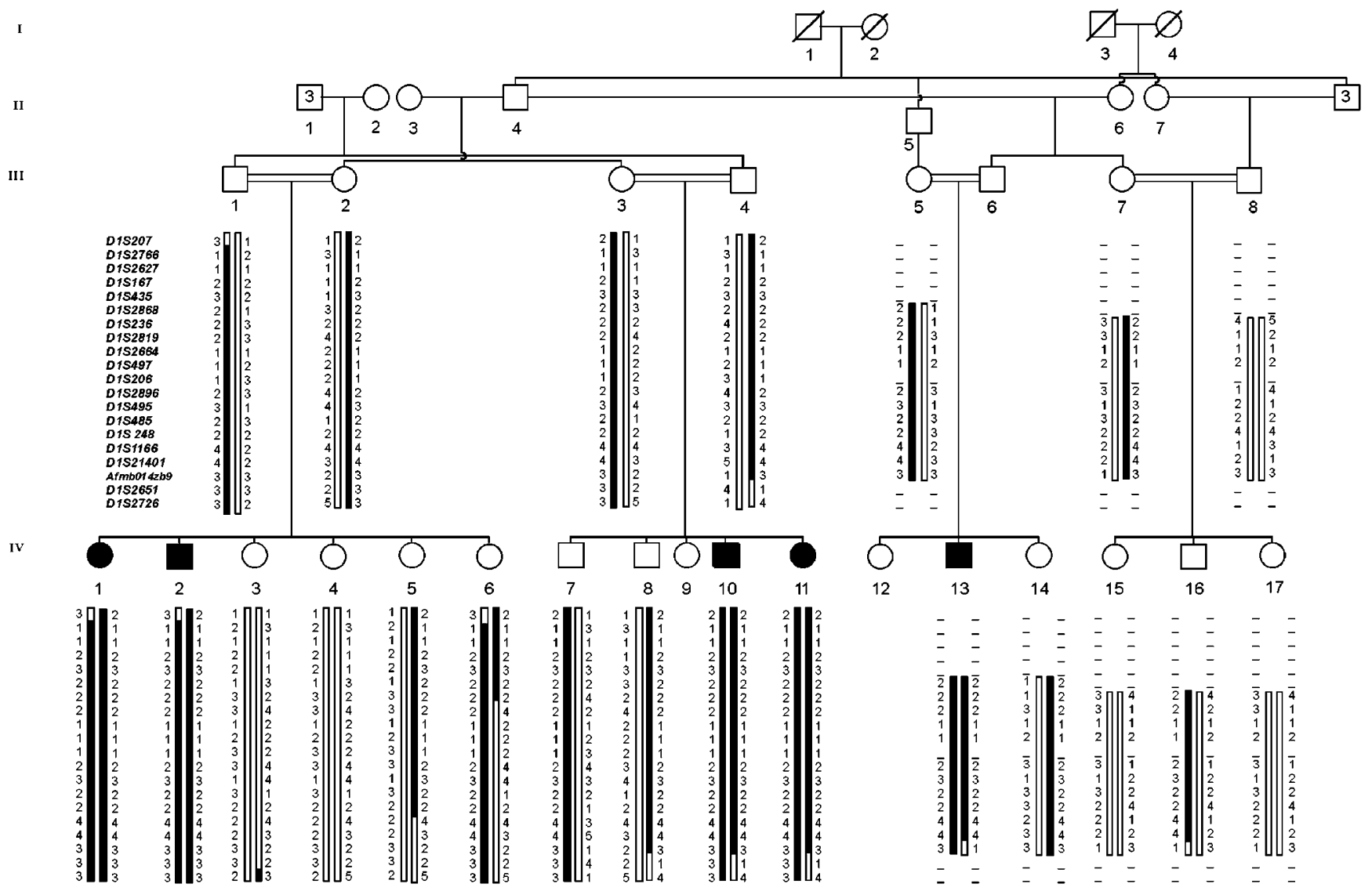

Figure 1 Haplotype analysis of DFNB32 family with nonsyndromic hearing impairment. Blackened circles and squares indicate affected members. Haplotypes for 20 polymorphic markers from the 1p13.3-22.1 chromosomal region and obligate recombination events are indicated. The haplotype assumed to carry the disease allele is indicated by the black bar. 
Linkage analysis was performed using the linkage 5.1 program. ${ }^{4}$ Two-point lod scores were calculated with the Mlink program. Deafness was assumed to be inherited in a recessive manner with complete penetrance. Recombination frequencies were assumed to be equal for males and females. An estimated frequency of $10^{-4}$ was used for the disease gene. The allele frequencies of the polymorphic markers were assumed to be equal.

\section{Mutation analysis}

Each of the 68 coding exons of COL11A1 and their flanking splicing sites were analysed by conformation sensitive gel electrophoresis (CSGE) according to Annunen et al. ${ }^{5}$ and at least 30 exons were sequenced using an ABI 377 automated sequencer. Sequences were compared with those of the different transcript variants of human COL11A1.

\section{Results and discussion}

Twenty-two individuals (five affected and 17 unaffected) from a large consanguineous Tunisian family affected with congenital autosomal recessive deafness, were investigated (Figure 1). The audiometric tests showed, for all affected individuals, a loss of hearing greater than $70 \mathrm{~dB}$. All affected individuals are otherwise healthy, with normal life spans and without dysmorphic or other abnormal findings.

In order to map the gene responsible for deafness, we performed linkage analyses with microsatellite markers corresponding to the previously identified loci (http:// www.uia.ac.be./dnalab/hhh/). For each of the candidate location we genotyped three markers within each locus selected based on published linkage study. No linkage was found indicating the involvement of a novel locus in this family. Therefore, we undertook a screening of the whole genome using microsatellite markers at intervals of $10 \mathrm{~cm}$. A linkage was detected only with locus D1S206 on chromosome 1, thereby defining a novel deafness locus, DFNB32. In order to confirm linkage and for fine mapping the genetic interval, 18 additional polymorphic microsatellite markers from the Généthon panel (http://cedar.genetics. soton.ac.uk/pub/chrom1/map.html), were typed (Figure 1). Significant two-point lodscores were obtained with five microsatellite markers with a maximum of 4.36 for D1S2896 at a recombination fraction $\theta=0.00$ (Table 1). Haplotype analysis disclosed key recombination events between D1S1166 and afmb014zb9 in affected individual IV:13, defining the centromeric boundary of the disease interval (Figure 1). To refine the centromeric limit, we generated a new microsatellite marker D1S21401. This marker was named according to the name of the BAC clone. No recombination was detected and a maximum lodscore of 4.96 was obtained with this marker. The telomeric limit of the interval is determined by a normal hearing individual IV:6, with recombination events excluding markers telomeric to D1S2868 (Figure 1). Therefore, the DFNB32 locus lies within the $16 \mathrm{Mb}$ region delimited by
D1S2868 and afmb014zb9 markers (http://www.genome. ucsc.edu/cgi-bin/hgGateway?db=hg11).

The DFNB32 critical region overlap with DFNA37 locus (http://www.uia.ac.be./dnalab/hhh/). There are two possible explanations for this finding. Firstly, the two deafness disorders could be caused by mutations in the same gene which would map within the overlapping interval of the two loci. On the other hand, the possibility of two deafness-related genes lying close to each other on 1p13.3-22.1 cannot be ruled out. Instances of both phenomena have been reported in previous literature. Mutations of Cx26 gene can cause nonsyndromic recessive (DFNB1) and dominant (DFNA3) deafness. ${ }^{6,7}$ On the other hand, two distinct genes, $C \times 26$ and $C x 30$, account for deafness segregating with both DFNB1 and DFNA3 locus. ${ }^{6-10}$ So, only the isolation of DFNB32 and DFNA37 genes is expected to elucidate the relationship between the two disorders.

Moreover, several DFNB genes have been shown to be responsible of isolated and syndromic forms of deafness (http://www.uia.ac.be./dnalab/hhh/). This has been the case for the MYO7A gene. Mutations of MYO7A can cause both nonsyndromic hearing impairment (DFNB2 and DFNA11) and syndromic deafness (USH1B). ${ }^{11-13}$ The DFNB32 region contains the COL11A1 gene responsible for 2 syndromic deafness, Marshall and Stickler syndromes. ${ }^{14,15}$ A search of the Human Cochlear cDNA Library and EST Database (http://hearing.bwd.harvard.edu/cochlearcdnalibrary.htm) revealed five ESTs expressed mapping within the 1p13.322.1 area (Table 2). The region syntenic to the DFNB32 interval is located on the murine chromosome 3. Among the numerous deaf mouse mutants which have been reported (http://www.ihr.mrc.ac.uk/hereditary/Mutants

Table 1 Markers with significant two-point lodscores and their respective map position according to (http://www.genome.ucsc.edu)

\begin{tabular}{lll}
\hline $\begin{array}{l}\text { Microsatellite } \\
\text { marker }\end{array}$ & $\begin{array}{l}\text { Lodscore } \\
(\theta=0.00)\end{array}$ & Map position \\
\hline D1S2819 & 3.27 & chr1:95828442-96028775 \\
D1S497 & 3.61 & chr1:98521457-98721717 \\
D1S2896 & 4.36 & chr1:102692505-102892868 \\
D1S495 & 3.91 & chr1:103290712-103491143 \\
D1S21401 & 4.96 & chr1:108946011-108946149 \\
\hline
\end{tabular}

Table 2 ESTs mapped in the DFNB32 interval

\begin{tabular}{lll}
\hline EST & Position & Gene \\
\hline N71903 & $93524450(1 \mathrm{p} 22.1)$ & Caloponin 3 \\
H88637 & $95679364(1 \mathrm{p} 21.3)$ & $\begin{array}{l}\text { Loc50999 } \\
\text { N67259 }\end{array}$ \\
$\begin{array}{ll}\text { Eukaryotic translation } \\
\text { elongation factor 1 }\end{array}$ \\
AW023171 & $100840122(1 \mathrm{p} 21.2)$ & $\begin{array}{l}\text { unknown } \\
\text { H89903 }\end{array}$ \\
\hline
\end{tabular}


Table.shtml), four (Chondrodysplasia, Osteopetrosis colony stimulating factor $1 \mathrm{KO}$, Droopy ear, Varttint-waddler) have been mapped to the orthologous region of chromosome 1p13.3-22.1. Therefore, it is reasonable to propose that DFNB32 and these mutants may represent defects of the same gene. The gene responsible for the chondrodysplasia mutant is the Col11a1. Therefore, the COL11A1 gene was considered as an excellent candidate because: (i) it is responsible for two syndromic deafness, (ii) it is expressed in the cochlea, and (iii) mutations in the homologue mouse mutant produce hearing impairment. In order to investigate COL11A1 as a candidate gene, we performed CSGE and sequence analysis. Analysis of the COL11A1 coding region in an affected family member disclosed 21 sequence variants. These variants have previously been detected in several unaffected individuals (unpublished data), thus ruling out their involvement in the disease pathogenesis. In addition to the COL11A1, the genes corresponding to the ESTs found are being screened for deafness-causing mutations.

In conclusion, the hearing disorder in the pedigree investigated maps to a new locus, DFNB32. Localisation of the locus DFNB32 is a first step towards the identification of a new gene that controls development and/or maintenance of normal hearing.

\section{Acknowledgements}

We are grateful to the families members for their participation in this study. This work was supported by 'Secrétariat d'Etat à la Recherche Scientifique et à la Technologie' (Tunisia) and Louisiana Gene Therapy Consortium (New Orleans, LA, USA) and HCA-The Health Care Company (Nashville, TN, USA) to L Ala-Kokko.

\section{References}

1 Morton NE: Genetic epidemiology of hearing impairment. Ann NY Acad Sci 1991; 630: 16-31.
2 Cohen MM, Gorlin RJ: Epidemiology, etiology and genetic patterns; in Gorlin RJ, Toriello HV, Cohen MM (eds): Hereditary Hearing Loss and its Syndromes. Oxford: Oxford University Press, 1995, pp 9-21.

3 Gorlin RJ: Genetic hearing loss with no associated abnormalities; in Gorlin RJ, Toriello HV, Cohen MM (eds): Hereditary Hearing Loss and its Syndromes. Oxford: Oxford University Press, 1995, pp $43-$ 61.

4 Lathrop GM, Lalouel JM: Easy calculations of lod scores and genetic risks on small computers. Am J Hum Genet 1984; 36: $460-465$.

5 Annunen S, Körkkö J, Czarny M et al: Splicing mutations of 54-bp exons in the COL11A1 gene cause Marshall syndrome, but other mutations cause overlapping Marshall/Stickler phenotypes. Am J Hum Genet 1999; 65: 974-983.

6 Kelsell DP, Dunlop J, Stevens HP et al: Connexin 26 mutations in hereditary non-syndromic sensorineural deafness. Nature 1997; 387: $80-83$.

7 Denoyelle F, Lina-Granade G, Plauchi $\mathrm{H}$ et al: Connexin 26 gene linked to a dominant deafness. Nature 1998; 393: 319-320.

8 Griffa A, Wagner CA, D'ambrosio L et al: Mutations in GJB6 cause nonsyndromic autosomal dominant deafness at DFNA3 locus. Nat Genet 1999; 23: 16-18.

9 Lerer I, Sagi M, Bet-Neriah Z, Wang Y, Levi H, Abeliovich D: A deletion mutation in GJB6 cooperating with a GJB2 mutation in trans in non-syndromic deafness: A novel founder mutation in Ashkenasi Jews. Hum Mutat 2001; 18: 460.

10 del Castillo I, Villamar M, Moreno-Pelayo MA et al: A deletion involving the connexin 30 gene in nonsyndromic hearing impairment. N Engl J Med 2002; 346: 243-249.

11 Weil D, Blanchard S, Kaplan J et al: Defective myosin VIIA gene responsible for Usher syndrome type 1B. Nature 1995; 374: $60-$ 61.

12 Weil D, Kussel P, Blanchard S et al: The autosomal recessive isolated deafness, DFNB2, and the Usher 1B syndrome are allelic defects of the myosin-VIIA gene. Nat Genet 1997; 16: 191-193.

13 Liu XZ, Walsh J, Tamagawa Y et al: Autosomal dominant nonsyndromic deafness caused by a mutation in the myosin VIIA gene. Nat Genet 1997; 17: 268-269.

14 Richards AJ, Yates JR, Williams R et al: A family with Stickler syndrome type 2 has a mutation in the COL11A1 gene resulting in the substitution of glycine 97 by valine in $\alpha 1(\mathrm{XI})$ collagen. Hum Mol Genet 1996; 5: 1339-1343.

15 Griffith AJ, Sprunger LK, Sirko-Osadsa DA, Tiller GE, Meisler MH, Warman ML: Marshall syndrome associated with a splicing defect at the COL11A1 locus. Am J Hum Genet 1998; 62: 816-823. 